\title{
InterCriteria Analysis applied to data from Euro Health Consumer Index for comparing the healthcare systems' performance in time
}

\author{
Veselina Bureva $^{1}$ and Nikolay Andreev ${ }^{2}$ \\ ${ }^{1}$ Intelligent Systems Laboratory \\ "Prof. Dr. Assen Zlatarov" University, \\ 1 "Prof. Yakimov" Blvd., Burgas 8010, Bulgaria \\ e-mail: vbureva@btu.bg \\ ${ }^{2}$ Transfusion Hematology Department, Saint Anna Hospital \\ 1 Dimitar Mollov Str., Sofia 1750, Bulgaria \\ e-mail: imuno chemeabv.bg
}

Received: 12 October 2019 Revised: 5 November 2019 Accepted: 11 November 2019

\begin{abstract}
Euro Health Consumer Index provides assessments for consumer services satisfaction of national healthcare systems. The healthcare rankings for the years 2014, 2015, 2016 and 2018 are observed. Intercriteria analysis is applied over the healthcare datasets for providing comparison to the Euro Health Consumer Index in the years. Summarized application over the healthcare rankings using the Aggregated ICA method is presented. Thereafter the results of Intercriteria analysis for consumer satisfaction from healthcare systems in the years 2014, 2015, 2016 and 2018 are discussed separately.
\end{abstract}

Keywords: Euro Health Consumer Index, Intercriteria analysis, Healthcare systems, Rankings. 2010 Mathematics Subject Classification: 03 E72.

\section{Introduction}

The Health Consumer Powerhouse (HCP) published Euro health consumer index reports for investigating the consumer-related healthcare in Europe. Euro health consumer index datasets present measurements for the performance of national healthcare systems by evaluating accessibility, patient rights and information, treatment results, range and reach of services, 
prevention score and pharmaceutical use. The healthcare rankings evaluate the health systems of 35 countries by 6 sub-disciplines. The countries are the following:

- Switzerland

- The Netherlands

- Norway

- Denmark

- Belgium

- Finland

- Luxembourg

- Sweden

- Austria

- Iceland

- France

- Germany
- Portugal

- The Czech Republic

- Estonia

- United Kingdom

- Slovakia

- Serbia

- Spain

- Italy

- Slovenia

- Ireland

- Montenegro

- Croatia
- North Macedonia

- Cyprus

- Malta

- Lithuania

- Greece

- Latvia

- Bulgaria

- Poland

- Hungary

- Romania

- Albania

The 6 sub-disciplines in Euro Health Consumer Index have the following form:

1) Patient rights and information score;

2) Accessibility (waiting times for treatment) score;

3) Outcomes score;

4) Range and reach of services score;

5) Prevention score;

6) Pharmaceuticals score.

The sub-disciplines are based on 46 indicators evaluated by the three grade scale: green score, amber score and red score representing the states for good score- 3 points, immediate score2 points and not good score-1 point. The country score of sub-disciplines is calculated as a percentage of the maximum possible. Thereafter, the sub-discipline scores were multiplied by the weight coefficients. The methodology is presented in [10-13, 15].

InterCriteria analysis (ICA) $[5,6,8]$ is based on the theories of intuitionistic fuzzy sets $[4,7]$ and index matrices [3]. The aim of the selected method is to investigate the possible relationships between the object according to the selected criteria. Pairwise comparison of pairs of values in the input matrix is made. Two counters are incrementing depending on the type of the relation: " $<$ " or ">". Thereafter the degree of membership and the degree of non-membership are calculated. The steps of the procedure of applying the InterCriteria Analysis are described in [6]. The results are determined according the following scale (Figure 1):

\begin{tabular}{|c|c|c|c|c|c|c|c|c|c|c|c|}
\hline & \multicolumn{11}{|c|}{ TYPE OF CONSONANCE } \\
\hline $\begin{array}{l}\text { DEGREES OF } \\
\text { CORRELATION }\end{array}$ & $\begin{array}{c}\text { Strong } \\
\text { Negative } \\
\text { Consonance } \\
\text { (SNC) } \\
\end{array}$ & $\begin{array}{c}\text { Negative } \\
\text { Consonance } \\
\text { (NC) }\end{array}$ & $\begin{array}{c}\text { Weak Negative } \\
\text { Consonance } \\
\text { (WNC) }\end{array}$ & $\begin{array}{c}\text { Weak } \\
\text { Dissonance } \\
\text { (WD) }\end{array}$ & $\begin{array}{c}\text { Dissonance } \\
\text { (D) }\end{array}$ & $\begin{array}{c}\text { Strong } \\
\text { Dissonance } \\
\text { (SD) }\end{array}$ & $\begin{array}{c}\text { Dissonance } \\
\text { (D) }\end{array}$ & $\begin{array}{c}\text { Weak } \\
\text { Dissonance } \\
\text { (WD) }\end{array}$ & $\begin{array}{c}\text { Weak } \\
\text { Positive } \\
\text { Consonance } \\
\text { (WPC) }\end{array}$ & $\begin{array}{c}\text { Positive } \\
\text { Consonance } \\
(P C)\end{array}$ & $\begin{array}{c}\text { Strong Positive } \\
\text { Consonance } \\
\text { (SPC) }\end{array}$ \\
\hline & {$[0 ; 0,05]$} & {$[0,05 ; 0,15)$} & {$[0,15 ; 0,25)$} & {$[0,25 ; 0,33)$} & {$[0,33 ; 0,43)$} & {$[0,43 ; 0,57)$} & {$[0,57 ; 0,67)$} & {$[0,67 ; 0,75)$} & {$[0,75 ; 0,85)$} & {$[0,85 ; 0,95)$} & {$[0,95 ; 1]$} \\
\hline
\end{tabular}

Figure 1. Scale for determination of the type of the correlations between the criteria 
ICA is successfully applied in investigations from different science topics: evaluating of university rankings [18, 19], neural networks preprocessing procedure [21], genetic algorithms $[16,20]$, the global competitiveness reports [9], chemical research [24, 25] and etc. In [26] an application of the ICA approach to data connected with health-related quality of life was presented. Health-related quality of life has been used in medicine and public health as a reliable outcome measure and a needs assessment frame [1, 2, 22, 27]. In [23] the ICA method is applied for studying some statistical data for registered patients with oncological diseases for 2018 in Burgas.

\section{Application of the InterCriteria Analysis to healthcare rankings for comparing the healthcare systems performance in time}

The first application of the Intercriteria analysis over the Euro Health Consumer Index determines relationships between the countries according to the sub-disciplines for 2018 [14]. In the current paper this investigation is continued. The Intercireria analysis is applied consequently for the years 2015, 2016 and 2018 to determine possible patterns for consumer satisfaction of the services provided by the national healthcare systems in countries. The process of discovering unseen dependencies in procedure of providing consumer services from the national healthcare systems in the countries can be helpful for their clustering. The healthcare rankings for the years 2015, 2016 and 2018 are visualized in the Fig. 2 by radar diagrams. The patient rights and information score is presented by dark blue. Outcomes score is denoted by green line. Range and reach of services score is presented by purple color. Prevention score is colored in light blue. Pharmaceuticals score is visualized by yellow/orange line.
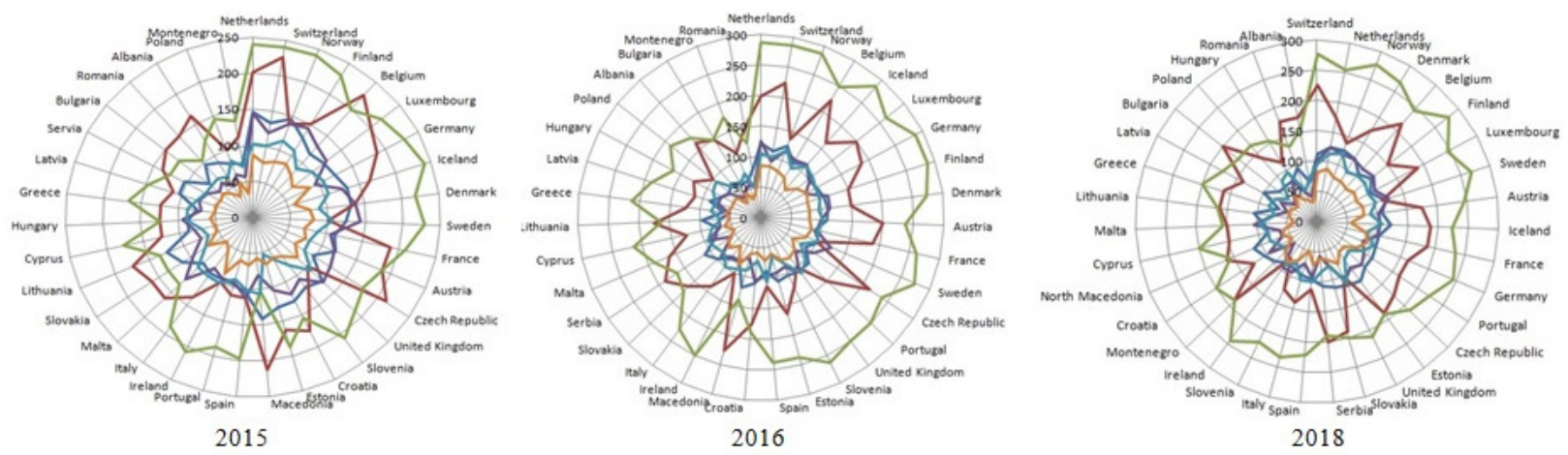

Figure 2. Radar diagrams of the healthcare rankings

\subsection{Application of the InterCriteria analysis over healthcare rankings using Aggregated IcRA method (3-dimensional case)}

Euro health consumer index reports for the years 2014, 2015, 2016 and 2018 are observed. The order of countries in the reports is sorted to be the similar in each table. The countries Scotland and Bosnia and Herzegovina are removed from the Euro health consumer index report for 2014. Four tables containing evaluations of the national healthcare systems of 35 countries according six sub-disciplines are used for Aggregated ICA application. Actually the input information is 
presented as a 3-dimensional structure - an OLAP cube (Figure 3). The healthcare datasets containing information about 3 dimensions are investigated.

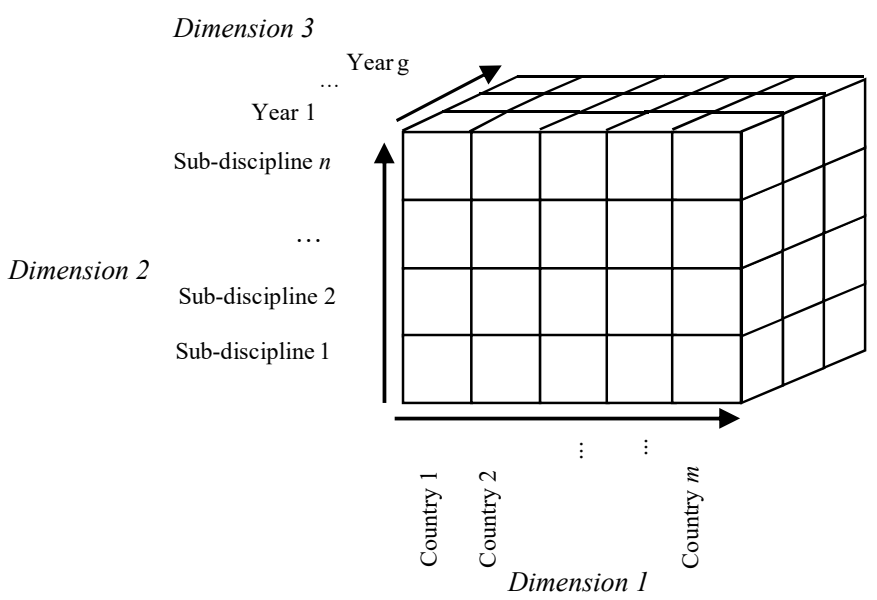

Figure 3. 3-dimensional representation of the healthcare datasets

The Aggregated InterCriteria analysis is used to investigate the three-dimensional input healthcare dataset. The method applies Stardard Intercriteria analysis over the four input tables for the years 2014, 2015, 2016, 2018. Therafter the aggregation at each value is calculated. The result includes aggregated matrix with degrees of membership and aggregated matrix with degrees of non-memberships. The application of ICA over Euro health consumer index is processed using ICrAData software [17]. The results from the Aggregated InterCriteria analysis appled to the three-dimensional dataset for healthcare systems have the following form (Table 1):

\begin{tabular}{|c|c|c|}
\hline Degrees of Correlation & Type of consonance & Number of pairs \\
\hline$[0,57 ; 0,67)$ & Dissonance (D) & 28 \\
\hline$[0,67 ; 0,75)$ & Weak Dissonance (WD) & 60 \\
\hline$[0,75 ; 0,85)$ & Weak Positive Consonance (WPC) & 179 \\
\hline$[0,85 ; 0,95)$ & Positive Consonance (PC) & 294 \\
\hline$[0,95 ; 1]$ & Strong Positive Consonance (SPC) & 36 \\
\hline
\end{tabular}

Table 1. Results of the application of Aggregated InterCriteria to healthcare rankings

The number of pairs of countries having similar healthcare systems performance is 509 . These pairs of countries have different degrees of dependence according to the obtained results: 36 pairs of countries are in strong positive consonance; 294 pairs of countries are in positive consonance and 179 pairs of countries are in weak positive consonance. The pairs of countries having independent healthcare systems are 88: 60 pairs of countries in weak dissonance and 28 
pairs of countries in dissonance. The received outcomes from Aggregated InterCriteria analysis are visualized in the intuitionistic fuzzy triangle (Fig.4). Pink points present the pairs of countries in dissonance and weak dissonance. Green points vizualize the pairs of countries in strong positive consonance, positive consonance and weak positive consonance.

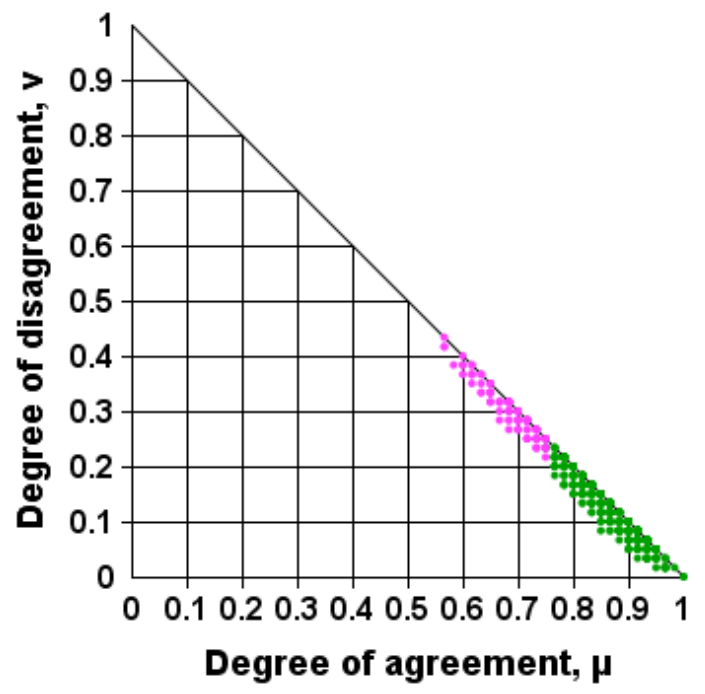

Fig.4 Results of the application of the aggregated InterCriteria Analysis over healthcare rankings

The pairs of countries with strong dependencies in their national healthcare systems performance are the following:

- The Netherlands- • Belgium-Czech Republic; - Switzerland-Slovenia,

Finland;

- Belgium-Finland;

- Finland-Luxembourg;

- Switzerland-Austria,

- Switzerland-Iceland;

- Switzerland-Portugal;

- Austria-Portugal;

- Iceland-Portugal;

- Switzerland-Cyprus;

- Portugal-Cyprus;

- Italy-Greece;

- Switzerland-Latvia;
- Finland-Czech Republic;

- Switzerland-Estonia;

- Portugal-Estonia;

- Switzerland-Slovakia;

- Austria-Slovakia;

- Portugal-Slovakia;

- Portugal-Slovenia;

- Austria-Latvia;

- Portugal-Latvia;

- Serbia-Bulgaria;

- Cyprus-Poland;
- The Netherlands-Slovenia;

- Finland-Slovenia;

- Germany-Montenegro;

- Austria-Croatia;

- Slovakia-Croatia;

- Switzerland-Croatia;

- Portugal-Croatia;

- Italy-Poland;

- Serbia-Romania;

- Bulgaria-Albania

The pairs of countries with independent behavior according to the functioning of their national healthcare systems are: 
- Sweden-Germany;

- Sweden-Serbia;

- United Kingdom-Serbia;

- Sweden-Italy;

- Denmark-Ireland;

- Belgium-Ireland;

- Iceland-Ireland;

- Czech Republic-Ireland;

- Estonia-Ireland;

- Slovakia-Ireland;
- Serbia-Ireland;

- Sweden-Montenegro;

- Ireland-Croatia;

- Sweden-Macedonia;

- United Kingdom-Macedonia;

- Ireland-Macedonia;

- Ireland-Lithuania;

- Sweden-Greece;

- United Kingdom-Bulgaria;

- Ireland-Bulgaria;
- Sweden-Bulgaria;

- Sweden-Poland;

- Sweden-Hungary;

- Sweden-Romania;

- United KingdomRomania;

- Sweden-Albania;

- United KingdomAlbania;

- Ireland-Albania.

\subsection{Investigating of the healthcare rankings in the years}

In the current section the comparison between the national healthcare systems of the countries in the years is investigated. The aim is to observe the possible trends of dependencies or independencies between the countries in the selected years. The results of Intercriteria analysis applied to the datasets from healthcare rankings are presented in the Table 2.

\begin{tabular}{|c|c|c|c|c|}
\hline \multirow{2}{*}{$\begin{array}{c}\text { Degrees of ICA } \\
\text { dependence }\end{array}$} & Type of ICA dependence & \multicolumn{3}{|c|}{ Number of pairs } \\
\cline { 3 - 5 } & Dissonance (D) & $\mathbf{2 0 1 8}$ & $\mathbf{2 0 1 6}$ & $\mathbf{2 0 1 5}$ \\
\hline$[\mathbf{0 , 3 3} ; \mathbf{0 , 4 3 )}$ & Strong Dissonance (SD) & 21 & 7 & 0 \\
\hline$[\mathbf{0 , 4 3 ; 0 , 5 7 )}$ & Dissonance (D) & 9 & 15 & 18 \\
\hline$[\mathbf{0 , 5 7 ; 0 , 6 7 )}$ & Weak Dissonance (WD) & 81 & 87 & 116 \\
\hline$[\mathbf{0 , 6 7 ; 0 , 7 5 )}$ & Weak Positive Consonance (WPC) & 116 & 130 & 129 \\
\hline$[\mathbf{0 , 7 5 ; 0 , 8 5 )}$ & Positive Consonance (PC) & 299 & 315 & 292 \\
\hline$[\mathbf{0 , 8 5} \mathbf{0 , 9 5}$ & Strong Positive Consonance (SPC) & 65 & 43 & 40 \\
\hline$[\mathbf{0 , 9 5 ;}]$ & & &
\end{tabular}

Table 2. Results of the InterCriteria Analysis application to the healthcare systems rankings in the years

The pairs of countries with strong correlations are 65 in 2018, 43 in 2016 and 40 in 2015. The pairs of countries with close relationships in the functioning of their national healthcare systems are 299 in 2018, 315 in 2016 and 282 in 2015. The pairs of countries having the national healthcare systems with weak dependencies of providing consumers services are 116 in 2018 , 130 in 2016 and 129 in 2015. The pairs of countries in weak dissonance are 81 in 2018, 87 in 2016 and 116 in 2015. The pairs of countries in dissonance are 15 in 2018, 15 in 2016 and 18 in 2015. The pairs of countries which are the most independent (strong dissonance) are 21 in 2018, 7 in 2016 and 2 in 2015. The results of the InterCriteria Analysis application over datasets for healthcare rankings are presented in the intuitionistic fuzzy triangle (Figure 5). The Euro Health Consumer Index is analyzed and the outcomes are visualized depending on the selected year of the investigation. 


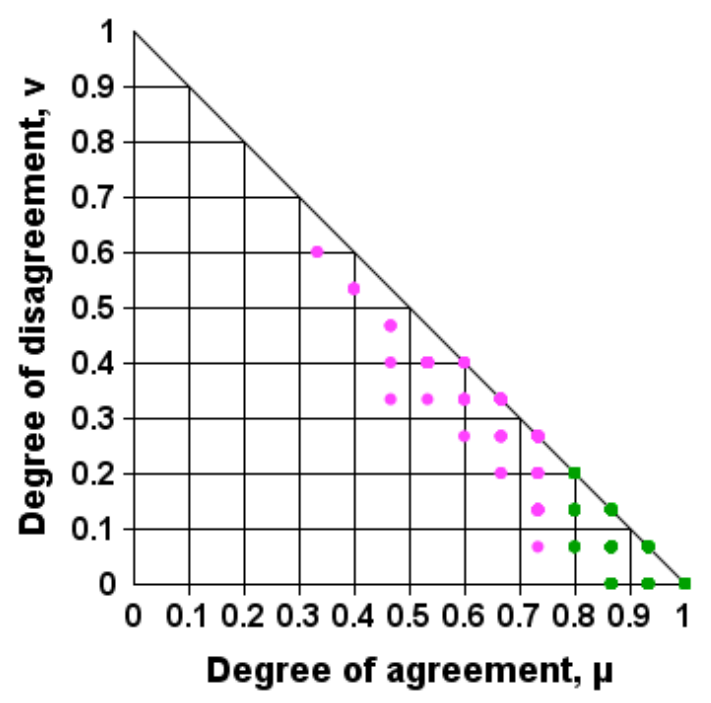

a) 2018

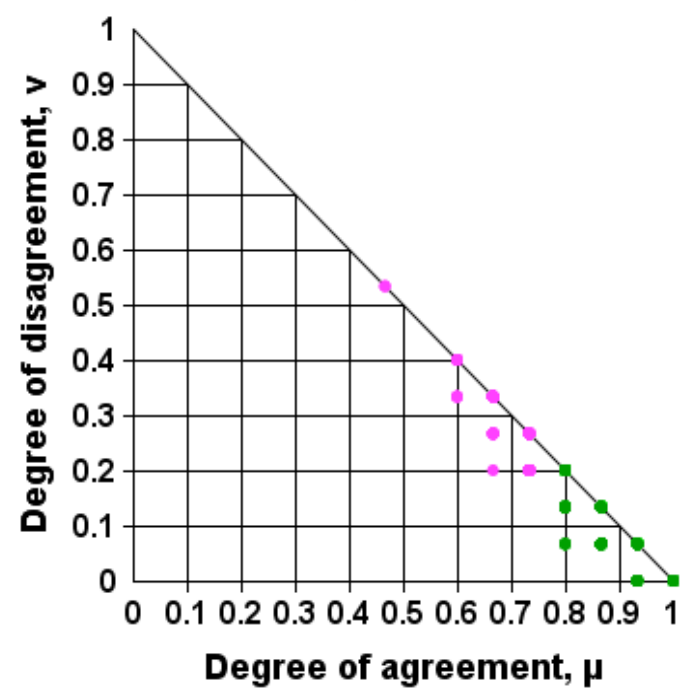

c) 2015

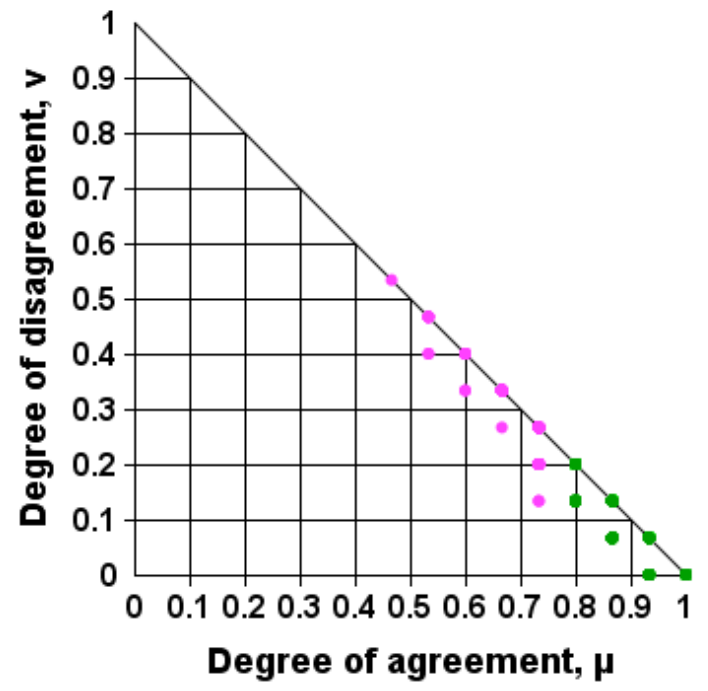

b) 2016

Figure 5. Results of the InterCriteria Analysis application over datasets for healthcare rankings in the years

The pair of countries with strong dependencies in their national healthcare systems performance for 3 years is "Switzerland-Portugal". The pairs of countries in strong positive consonance for 2 years have the following form:

- Belgium - Finland;

- Finland - Luxembourg;

- Switzerland - Austria;

- Norway - Austria;

- Norway - Portugal;

- Austria - Portugal;

- Bulgaria-Romania

- Belgium - Czech Republic;
- Denmark - Czech Republic;

- Estonia-Slovakia;

- Estonia-Croatia,

- Slovakia - Lithuania;

- Croatia - Lithuania;

- Greece - Poland;

- Croatia-Slovakia;

- Italy - Poland. 


\section{Results}

The results from the application of aggregated InterCriteria Analysis over three-dimensional representation of the healthcare rankings are investigated. The comparison between the countries is made. The following conclusions are obtained:

- The pairs of countries in strong positive consonance have similar healthcare systems functioning according to the viewpoint of consumers in time. These pairs of countries have strong similarities.

- The pairs of countries in positive consonance have similar behavior according to the investigated sub-disciplines. Obviously the results present similarities in consumer services of the healthcare systems.

- The pairs of countries in weak positive consonance have close relationships between the years. They have similar way of customer service of their healthcare systems.

- The pairs of countries in dissonance and weak dissonance have independent consumer services of their national healthcare systems. These pairs of countries haven't close relationships and similar patterns in their healthcare systems.

\section{Results about national healthcare system of Slovakia}

The outcomes for Slovakia from the application of Aggregated InterCriteria analysis over threedimensional healthcare dataset have the following form.

- Dissonance (SD): Slovakia - Ireland;

- Weak Dissonance (WD): Sweden - Slovakia, United Kingdom - Slovakia, Slovakia Spain;

- Weak Positive Consonance (WPC): Slovakia - Spain, Slovakia - Greece;

- Positive Consonance (PC): Netherlands - Slovakia, Norway - Slovakia, Denmark Slovakia, Belgium - Slovakia, Finland - Slovakia, Luxembourg - Slovakia, Iceland Slovakia, France - Slovakia, Germany - Slovakia, Czech Republic - Slovakia, Estonia - Slovakia, Slovakia - Serbia;

- Strong Positive Consonance (SPC): Switzerland - Slovakia, Austria - Slovakia, Portugal - Slovakia.

The consumer service of national healthcare system of Slovakia is the most similar to the national healthcare systems of Switzerland, Austria and Portugal. The most independent behavior according to the investigated sub-disciplines is found between the national healthcare systems of Slovakia and Ireland.

Via the comparison of the results over the period of research $(2018,2016,2015)$ the following outcomes are obtained:

- The pairs of countries "Switzerland-Portugal" has been in strong positive consonance for three years. The relationships between the countries are strong. The countries Switzerland and Portugal have dependencies in their healthcare systems providing consumer services.

- 16 pairs of countries have been in strong positive consonance for 2 years. The behaviour of these national healthcare systems is stable with respect to the process of providing consumer services in time. 
- The pairs of countries "Sweden-Ireland" is the most independent one over the years. This pair of countries appears two years in strong dissonance. The national healthcare systems functioning in these countries are different.

\section{Conclusion}

The InterCriteria Analysis is used to find some hidden patterns in the data from Euro Health Consumer Index. Ratings of European healthcare systems are compiled over the years. The data is analyzed to identify the best correlations between the countries, to discover dependent and independent countries and the relationships between them. The comparison can help describing the behaviour of the analysed countries and their assessment. In the next research, the authors will analyze the indicators of sub-disciplines individually. In the future research works, the authors will analyze the dependencies in Euro health index and Euro diabetes index.

\section{Acknowledgements}

The authors are thankful for the support provided by the Bulgarian National Science Fund under Grant Ref. No. KP-06-N22/1/2018 "Theoretical research and applications of InterCriteria Analysis."

\section{References}

[1] Atanasov, A., Lefterov, E., Vasilev, V., Kehayov, A., Savov, M., Penchev, V., \& Dashkov, B. (2011). Evaluation of the quality of life in patients with various abdominal anastomoses in case of colon carcinoma, Regional Scientific Conference, ISBN 978 -954-397-023-0, Svilengrad, 17 - 19.11.2011, 110-112.

[2] Atanasov, A., Lefterov, E., Vasilev, V., Kehayov, A., Savov, M., Penchev, V. \& Polyanov, B. (2012). Evaluation of quality of life in patients operated on for colon carcinoma, Third International Medical Congress of SEEMF, Belgrade, Serbia, 12-15 September 2012, 42.

[3] Atanassov, K. (2014). Index Matrices: Towards an Augmented Matrix Calculus. Studies in Computational Intelligence Series, Vol. 573, Springer, Cham.

[4] Atanassov, K. (2012). On Intuitionistic Fuzzy Sets Theory, Springer, Berlin.

[5] Atanassov, K., Atanassova, V., \& Gluhchev, G. (2015). InterCriteria Analysis: Ideas and problems, Notes on Intuitionistic Fuzzy Sets, 21 (1), 81-88.

[6] Atanassov, K., Mavrov, D. \& Atanassova, V. (2014). InterCriteria Decision Making: A New Approach for Multicriteria Decision Making, Based on Index Matrices and Intuitionistic Fuzzy Sets. Issues in Intuitionistic Fuzzy Sets and Generalized Nets, 11, 1-8.

[7] Atanassov, K., Szmidt, E., \& Kacprzyk, J. (2013). On intuitionistic fuzzy pairs, Notes on Intuitionistic Fuzzy Sets, 19 (3), 1-13. 
[8] Atanassova, V., Doukovska, L., Michalíková, A., \& Radeva, I. (2016). Intercriteria analysis: from pairs to triples, Notes on Intuitionistic Fuzzy Sets, 22 (5), 98-110.

[9] Atanassova, V., Doukovska, L., Mavrov, D., \& Atanassov, K. (2014). InterCriteria Decision Making Approach to EU Member States Competitiveness Analysis: Temporal and Threshold Analysis., In P. Angelov et al. (eds), Intelligent Systems'2014, Advances in Intelligent Systems and Computing, 322, 95-106.

[10] Björnberg, A., \& Phang, A. (2019). Euro Health Consumer Index 2018 Report, Health Consumer Powerhouse, ISBN 978-91-980687-5-7.

[11] Björnberg, A. (2015). Euro Health Consumer Index 2014 Report, Health Consumer Powerhouse, ISBN 978-91-980687-5-7

[12] Björnberg, A. (2016). Euro Health Consumer Index 2015 Report, Health Consumer Powerhouse, 2016, ISBN 978-91-980687-5-7

[13] Björnberg, A. (2017). Euro Health Consumer Index 2016 Report, Health Consumer Powerhouse, ISBN 978-91-980687-5-7

[14] Bureva, V., Atanassov, K., \& Andreev, N. (2019). Intercriteria Analysis applied to Healthcare Rankings, Annual of Assen Zlatarov University, Burgas, Bulgaria, v. XLVIII, 1, (in press).

[15] Euro health consumer index, https://en.wikipedia.org/wiki/Euro_health_consumer_index

[16] Fidanova, S., \& Roeva, O. (2017). Comparison of Different Metaheuristic Algorithms based on InterCriteria Analysis, Journal of Computational and Applied Mathematics, Available online 7 August 2017, https://doi.org/10.1016/j.cam.2017.07.028

[17] Ikonomov, N., Vassilev, P., \& Roeva, O. (2018). ICrAData - Software for InterCriteria Analysis, Int. J. Bioautomation, 22 (1), 1-10.

[18] Krawczak, M., Bureva, V., Sotirova, E., \& Szmidt, E. (2016). Application of the InterCriteria Decision Making Method to Universities Ranking, In: Novel Developments in Uncertainty Representation and Processing, Vol. 401, Advances in Intelligent Systems and Computing, Springer, 365-372.

[19] Parvathi, R., Atanassova, V., Doukovska, L. Yuvapriya, C. \& Indhurekha, K. (2018). InterCriteria Analysis of rankings of Indian universities, Notes on Intuitionistic Fuzzy Sets, 24 (1), 99-109.

[20] Roeva, O., Vassilev, P., Fidanova, S., \& Paprzycki, M. (2016) InterCriteria Analysis of Genetic Algorithms Performance. In: Fidanova S. (eds) Recent Advances in Computational Optimization. Studies in Computational Intelligence, vol 655. Springer, Cham, 235-260.

[21] Sotirov, S., Atanassova, V., Sotirova, E., Bureva, V., \& Mavrov, D. (2015) Application of the Intuitionistic Fuzzy InterCriteria Analysis Method to a Neural Network Preprocessing Procedure. Proc. of 16th World Congress of the International Fuzzy Systems Association (IFSA), 9th Conference of the European Society for Fuzzy Logic and Technology (EUSFLAT), 30.06-03.07.2015, Gijon, Spain, 1559-1564. 
[22] Sotirov, S., Vankova, D., Vasilev, V., \& Sotirova, E. (2019). Clustering of Intercriteria Analysis Data Using a Health-Related Quality of Life Data, Lecture Notes in Computer Science, Vol. 11529, FQAS 2019: Flexible Query Answering Systems, 242-249

[23] Sotirova, E., Petrova, Y., \& Bozov, H. (2019). InterCriteria Analysis of oncological data of the patients for the city of Burgas, Notes on Intuitionistic Fuzzy Sets, 25 (2), 96-103.

[24] Stratiev, D., Shishkova, I., Nedelchev, A., Kirilov, K., Nikolaychuk, E., Ivanov, A., Sharafutdinov, I., Veli, A., Mitkova, M., Tsaneva, T., Petkova, N., Sharpe, R., Yordanov, D., Belchev, Z., Nenov, S., Rudnev, N., Atanassova, V., Sotirova, E., Sotirov, S., \& Atanassov, K. (2015). Investigation of relationships between petroleum properties and their impact on crude oil compatibility, Energy \& Fuels, 29 (12), 7836-7854.

[25] Stratiev, D., Sotirov, S., Shishkova, I., Nedelchev, A., Sharafutdinov, I., Veli, A., Mitkova, M., Yordanov, D., Sotirova, E., Atanassova, V., Atanassov, K., Stratiev, D., Rudnev, N., \& Ribagin, S. (2016). Investigation of relationships between bulk properties and fraction properties of crude oils by application of the intercriteria analysis, Petroleum Science and Technology, 34 (13), 1113-1120.

[26] Vankova, D., Sotirova, E. \& Bureva, V. (2015). An application of the InterCriteria Analysis approach to health-related quality of life, Notes on Intuitionistic Fuzzy Sets, 21 (5), 40-48.

[27] Vankova, D., Kerekovska, A., Kostadinova, T., \& Usheva, N. (2013). Health-related Quality of Life in the Community. Assessing the Socio-Economic, Demographic and Behav-ioural Impact on Health-related Quality of Life at a Community Level: Evidence from Bulgaria, Proceedings database, 2013, http://www.euroqol.org/uploads/media/EQ1 